\title{
Quadra Fechada
}

\section{Uma iniciativa dos cortadores de cana de Cosmópolis}

\author{
Ellen Gallerani Corrêa *
}

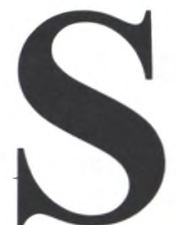

egundo estatísticas da Pastoral do Migrante, o Estado de São Paulo recebe todos os anos, durante o período da safra da canade-açúcar, cerca de 200 mil trabalhadores rurais migrantes que são empregados, predominantemente, na atividade de corte da cana. Estes trabalhadores são denominados migrantes temporários, já que, após trabalharem na safra da cana-deaçúcar por um período de 6 a 8 meses, voltam para os seus estados de origem. Entretanto, este deslocamento de trabalhadores rurais está ocorrendo no Brasil desde a década de 1960 quando surgem no país os complexos agroindustriais, os quais passam a demandar uma grande quantidade de trabalhadores para a produção agrícola em grande escala. Desta forma, como observa Silva (2006), apesar de estes trabalhadores serem chamados de migrantes temporários, esta migração se repete, desde o início da década acima citada, todos os anos, o que a torna permanentemente temporária.
Nos últimos anos, tornou-se recorrente na mídia a veiculação de matérias relatando a existência de precárias condições de trabalho nos canaviais paulistas e, até mesmo, casos de trabalho escravo. Fiscalizações do Ministério Público do Trabalho constataram que é freqüente o desrespeito aos direitos trabalhistas por parte de usineiros e fornecedores de cana-de-açúcar. Dentre as inúmeras irregularidades encontradas, as mais comuns são: trabalhadores sem registro na carteira de trabalho e sem equipamentos de proteção para o trabalho no corte da cana e alojamentos em péssimo estado de conservação e higiene.

Além do risco de terem seus direitos trabalhistas descumpridos pelos empregadores, estes trabalhadores estão constantemente sujeitos aos problemas que podem ser ocasionados pela forma de remuneração na qual se assenta o trabalho no corte da cana, a saber o salário por produção. Podemos identificar dois problemas principais gerados por esta modalidade de remuneração: a intensificação do ritmo de trabalho e a ausência de controle por parte dos trabalhadores de sua própria produção e, portanto, do valor de seus salários.

No primeiro caso, a intensificação do ritmo de trabalho ocorre em virtude do seguinte contexto: como os cortadores de cana recebem baixos salários e trabalham para garantir a subsistência, a intensificação do ritmo de trabalho é vista como um meio para garantir salários mais elevados. A aceleração do ritmo de trabalho pode acarretar conseqüências sérias ao trabalhador, como desidratação, cãibras, dores no corpo, convulsões e, nas situações mais graves, levá-lo à morte. De acordo com dados da Pastoral do Migrante, o excesso de esforço provocou, entre os anos de 2004 e 2007, 21 mortes na região canavieira do Estado de São Paulo. Em segundo lugar, a falta de controle por parte dos trabalhadores de sua própria produção, uma vez que esta varia de uma semana ${ }^{1}$ para outra, permite que, muitas vezes, os trabalhadores sejam 
enganados ao receberem por uma produção menor do que aquela que eles realmente realizaram.

$\mathrm{O}$ presente artigo tem como objetivo apresentar um sistema de controle da produção elaborado pelos cortadores de cana, em conjunto com a entidade sindical que representa a categoria, na cidade de Cosmópolis, localizada no interior do Estado de São Paulo, que tem como finalidade tanto garantir que os trabalhadores recebam exatamente por aquilo que produziram quanto assegurar o real valor do peso e do preço da tonelada da cana, uma vez que é a partir destas duas variáveis que se calcula o salário dos cortadores de cana.

\section{PRINCIPAIS \\ CARACTERÍSTICAS DOS TRABALHADORES EMPREGADOS NOS CANAVIAIS PAULISTAS}

O processo de desenvolvimento capitalista no campo, iniciado no Brasil a partir da década de 1960 , produziu uma série de conseqüências no meio rural $^{2}$. Dentre elas, estão a expropriação e expulsão do homem do campo e a expansão da relação de trabalho assalariada, principalmente $o$ assalariamento temporário. Desta forma, a mão-de-obra utilizada nos canaviais paulistas é formada tanto por trabalhadores que moram nas periferias das cidades vizinhas aos canaviais quanto por trabalhadores migrantes que, durante a safra da cana-de-açúcar, vêm trabalhar em São Paulo para complementar a renda proveniente de suas pequenas produções insuficientes.

De acordo com a definição de D'Incao (1984), o trabalhador assalariado rural compreende desde o pequeno produtor que se assalaria temporariamente nas empresas agrícolas, durante os meses de safra, para complementar a sua renda, até o trabalhador totalmente expropriado da terra que reside nas cidades, que se assalaria durante a colheita e faz "bicos" na entressafra. Segundo a autora, o que permite identificar estes trabalhadores é o caráter temporário e itinerante de seu trabalho, pois prestam serviço durante períodos determinados e se deslocam constantemente em busca de trabalho.

Assim sendo, a força de trabalho dos canaviais é formada por assalariados puros, que sobrevivem unicamente da venda de sua força de trabalho e moram nas periferias das cidades, e por meio-assalariados, pequenos produtores migrantes que se assalariam temporariamente para complementar a renda.

No que se refere aos trabalhadores migrantes, é possível perceber que estes são provenientes das regiões mais pobres do país, como os estados do Nordeste e o Vale do Jequitinhonha, região norte de Minas Gerais. Na grande maioria das vezes, são trabalhadores jovens e do sexo masculino que se deslocam para o Estado de São Paulo para trabalhar na safra da cana e, durante este período, moram em alojamentos construídos pelas usinas ou em pensões localizadas nas cidades-dormitório vizinhas aos canaviais.

Em pesquisas recentes, Silva (2006) constatou que está ocorrendo uma mudança da cartografia migratória, na medida em que está aumentando o número de migrantes provenientes de estados, como o Maranhão e o Piauí, que anteriormente possuíam uma pequena participação neste processo. Segundo a autora, este fenômeno pode ser explicado pelo fato de que, com a intensificação do ritmo de trabalho ocorrida nas últimas décadas (atualmente a média de produção de um cortador é de 12 toneladas de cana cortada por dia; na década de 80 era de 6 toneladas e, na década de 60 , de 3 toneladas), tornouse necessária a busca de novos migrantes que pudessem suprir a necessidade de trabalhadores jovens, já que a capacidade física é fator determinante para se alcançar uma meta de 12 toneladas diárias de cana cortada.

\section{O NASCIMENTO DA QUADRA FECHADA E A SUBSTITUIÇÃO DO SISTEMA DE “CAMPEÃO"}

As obras que tratam da temática do trabalho agrícola no setor canavieiro nos permitem verificar que o controle da própria produção sempre foi uma demanda entre os trabalhadores assalariados do corte da cana. Como são remunerados pelo que produzem e não pelo tempo de serviço prestado, estes trabalhadores reivindicam a garantia de que irão receber exatamente pelo volume de cana que cortaram, já que a pesagem da cana é feita nas balanças das usinas, ou seja, longe do controle dos trabalhadores.

Em 1986, os trabalhadores assalariados do corte da cana do Estado de São Paulo deflagraram uma greve que teve início nas cidades de Leme e Araras e se espalhou para outras regiões canavieiras do estado. A principal reivindicação dos trabalhadores era o pagamento por metro de cana cortado e não mais por tonelada como vinha sendo feito. Esta reivindicação previa que o preço do metro linear, de acordo com a variedade da cana (cana de primeiro corte, em pé, deitada, etc), deveria ser estabelecido no acordo coletivo de trabalho. Desta forma, no final do dia de trabalho, os trabalhadores receberiam um comprovante, chamado 
de "pirulito", no qual estariam especificados a quantidade de metros cortados e o valor do metro para aquela variedade de cana (Alves, 2006).

Os empresários do setor não aceitaram esta proposta, argumentando que era impossível adotar o pagamento por metro, uma vez que a unidade de medida utilizada em todas as fases do processo produtivo era a tonelada. Na verdade, segundo Alves, as usinas queriam impedir que os trabalhadores adquirissem o controle sobre o pagamento, pois, caso isto ocorresse, os empresários perderiam o principal meio de pressão para aumentar a produtividade do trabalho. Ao saber quanto ganham, os trabalhadores podem interromper $o$ corte quando querem ou quando acharem que já estão no limite de sua resistência. A greve de 1986 só chegou ao fim quando foi estabelecido o acordo de que o pagamento dos trabalhadores seria feito a partir da tonelada de cana convertida em metro linear e de que esta conversão poderia ser fiscalizada pelos trabalhadores.

A pesagem da cana e a conversão da tonelada em metro linear seriam realizadas através do sistema de "campeão", o qual consiste nas seguintes etapas: antes de se iniciar o corte de uma quadra ou talhão (área plantada com cana), um caminhão da usina, chamado de "campeão", é carregado com a cana colhida e medida em metros lineares de três pontos diferentes (amostras) da quadra; o caminhão leva a cana para a balança da usina; após a pesagem desta cana é realizada a conversão da tonelada de cana em metro linear, encontrando a paridade $\mathrm{x}$ metros $=\mathrm{x}$ toneladas. $\mathrm{A}$ partir do preço da tonelada, estabelecido no acordo coletivo de trabalho, encontra-se o valor do metro linear que servirá de base para o pagamento dos trabalhadores. $\mathrm{O}$ valor encontrado para as amostras é utilizado em toda a quadra. O problema deste sistema é que, em muitas usinas, costuma-se escolher os pontos da quadra onde a cana é mais fraca, e, portanto, com menor peso. Isto é feito para baixar o preço do metro de cana e, assim, pagar menos aos trabalhadores.

Segundo o acordo realizado na greve de 1986, todas as fases deste procedimento, inclusive a escolha dos pontos que serviriam como amostra da quadra, poderiam ser acompanhadas e fiscalizadas pelos trabalhadores. Entretanto, este sistema nunca funcionou, pois o trabalhador que se dispusesse a acompanhá-lo perderia praticamente meio-dia de trabalho, fazendo com que sua remuneração ficasse muito defasada. Além disso, aqueles que se dispõem a participar sentem-se marcados pelas usinas, fiscais e "gatos" ${ }^{3} \mathrm{e}$ temem pela perda do emprego (Alves, 2006).

$\mathrm{Na}$ cidade de Cosmópolis, a aferição da produção dos trabalhadores também era realizada através do sistema de "campeão" antes da implantação da quadra fechada. Segundo Paulo César de Lima, dirigente sindical do Sindicato de Empregados Rurais de Cosmópolis, o sistema de quadra fechada foi implantado na cidade em 1998. Neste ano, foi realizada uma paralisação, que teve a duração de apenas um dia, por uma turma (grupo de trabalhadores responsável pelo corte da cana de uma determinada quadra) que estava descontente com o preço pago pela cana, já que este estava muito baixo. Para resolver o impasse, um trabalhador sugeriu que fosse carregada e pesada a cana de toda a quadra em que estava trabalhando aquela turma. Após a pesagem, verificou-se que o peso da cana era maior do que o peso apresentado pelo "campeão". A partir deste momento, instalou-se o sistema de quadra fechada.

A quadra fechada funciona da seguinte forma: após os trabalhadores cortarem a cana de toda uma quadra (ou talhão), a qual, antes de ser cortada, é medida para se saber quantos metros lineares de cana existem nela, esta cana é colocada no caminhão e levada para a balança da usina; depois de ser realizada a pesagem, encontra-se o número de toneladas de cana por metro linear existente naquela quadra através da divisão do peso da cana pela quantidade de metros lineares da quadra; após encontrar a relação tonelada/metro ou $\mathrm{kg} / \mathrm{metro}$, insere-se nela o valor do preço da tonelada, o qual já foi definido no acordo coletivo, para se descobrir o preço do metro linear de cana.

A diferença entre o "campeão" e a quadra fechada é que, no primeiro, o preço do metro é definido a partir do peso de três amostras da quadra de cana e, na segunda, o preço é estipulado a partir do peso da cana de toda a quadra. A implantação deste sistema representa uma importante vitória para os trabalhadores, já que a principal demanda desta categoria sempre foi o controle de sua produção para que fossem evitadas perdas salariais. O sistema de quadra fechada, além de pesar toda a cana do talhão (evitando que sejam pesados apenas os pontos em que a cana tem um baixo peso) também estabelece a presença de fiscais na balança da usina para garantir que o peso da cana informado por esta, e no qual é baseado o salário do trabalhador, seja de fato o peso real. Segundo o sindicato da cidade, com este novo sistema, o salário dos trabalhadores chegou a ter um aumento de $30 \%$. Além disso, ficou comprovado que trabalhadores que 
cortavam 10,15 toneladas, na verdade, estavam cortando 20, 25 toneladas.

Atualmente, ficam três fiscais do sindicato na balança da usina de Cosmópolis conferindo a pesagem da cana. Além disso, o sindicato instalou na balança um microcomputador com um programa específico que permite controlar toda a cana que entra na usina e o seu respectivo peso. A usina é obrigada a fornecer ao sindicato o seu mapa agronômico, no qual deve constar: o mapa das quadras de cada fazenda que a usina possui, os metros lineares de cana de cada quadra e a estimativa das toneladas de cana correspondentes a estes metros. Toda semana é fixado nos ônibus que transportam os trabalhadores um relatório, que também vai para o sindicato, com o nome das quadras cortadas, o peso e a quantidade de metros lineares da quadra e o valor real e o valor estimado ${ }^{4}$ do $\mathrm{kg} / \mathrm{m}$. Este relatório serve para que o trabalhador possa compará-lo com o seu holerite e conferir se ele recebeu, de fato, os valores reais.

A usina de açúcar e álcool de Cosmópolis é a única usina do Estado de São Paulo que utiliza este modelo. De acordo com a entidade sindical dos cortadores de cana, algumas usinas e sindicatos já vieram até a cidade para conhecer o sistema e, futuramente, implantá-lo. O sistema de quadra fechada em Cosmópolis foi objeto de um documentário, intitulado Quadra Fechada, realizado por José Roberto Novaes, professor do Instituto de Economia da Universidade Federal do Rio de Janeiro (UFRJ) e estudioso da temática dos trabalhadores envolvidos no corte da cana. O documentário foi lançado em maio de 2007 em um congresso realizado no Rio de Janeiro.

De acordo com Silva (2006), a Delegacia Regional do Trabalho de São Paulo (DRT/SP) produziu um documento com uma série de medidas que deverão ser impostas às usinas com o intuito de acabar com a precarização das relações de trabalho e a superexploração dos trabalhadores. Entre estas medidas está a adoção do sistema de quadra fechada.

\section{CONSIDERAÇÕES FINAIS}

De um modo geral, este artigo procurou demonstrar como o sistema de quadra fechada soluciona um dos problemas acarretados pelo salário por produção: a falta de controle dos trabalhadores sobre a sua própria produção. Entretanto, esta forma de remuneração continua trazendo graves prejuízos aos trabalhadores, uma vez que a combinação entre salário por produção e baixos salários foi uma das formas mais eficientes encontradas pelas grandes empresas agrícolas para garantir a intensificação do ritmo de trabalho no campo e o máximo de produtividade. No século XIX, Marx já havia refletido sobre as peculiaridades do salário por produção e compreendido o seu caráter perverso, o que podemos perceber em sua seguinte passagem:

"Dado o salário por peça, é naturalmente interesse pessoal do trabalhador empregar sua força de trabalho o mais intensivamente possível, o que facilita ao capitalista elevar o grau normal de intensidade do trabalho. (...) evidencia-se que o salário por peça é a forma de salário mais adequada ao modo capitalista de produção" (Marx, 1994, pp. 640-42). Como os salários são baixos e dependem da quantidade de cana cortada, o trabalhador rural acaba trabalhando até o limite de suas forças para conseguir o melhor salário possível.

* Ellen Gallerani Corrêa é graduanda em ciências sociais pela Unicamp e integra o Centro de Estudo Rurais (CERES) da Unicamp.

\section{NOTAS}

1 - No Estado de São Paulo é mais comum a utilização, pelas usinas, do pagamento semanal.

2 - Para saber mais sobre o fenômeno de expansão capitalista no campo ver: COLETTI, Claudinei (1998), cap. 2.

3 - São chamados "gatos" aqueles que fazem o serviço de aliciamento de mãode-obra para as usinas. Os "gatos" são intermediários que recrutam os trabalhadores e os levam para o corte da cana nos canaviais. Na maioria das vezes, não são funcionários das usinas e deduzem sua remuneração do montante que lhes é entregue por estas para a realização do pagamento dos cortadores de cana.

4 - Como no sistema de quadra fechada, utiliza-se a cana de toda a quadra para se estabelecer o valor do $\mathrm{kg} / \mathrm{m}$ e, então, o preço do metro linear, este último só pode ser definido após os trabalhadores terminarem de cortar toda a cana. Desta forma, no final do dia de trabalho, o fiscal de frente passa aos trabalhadores um valor estimado. Caso o valor real seja maior, paga-se a diferença ao trabalhador; caso for menor, continua valendo o valor estimado.

\section{REFERÊNCIAS}

ALVES, F. J. C.

(2006) "Por que morrem os cortadores de cana?". Saúde e Sociedade, v. 15/3, p.90-98.

COLETTI, Claudinei

(1998) A estrutura sindical no campo. Campinas: Editora da Unicamp.

D'INCAO, Maria C.

(1984) Qual é a questão do bóia-fria? São Paulo: Brasiliense.

MARX, Karl

(1994) O Capital: crítica da economia política. Livro primeiro, v. II, $14^{a}$ edição. Rio de Janeiro: Bertrand Brasil.

SILVA, Maria A. M.

(2006) "A morte ronda os canaviais paulistas". Reforma Agrária. São Paulo, v. 33, no 2, p.111-143. 